\title{
DEVELOPMENT OF CSP USING CONVEX LENSES FOR DOMESTIC WATER HEATING
}

\author{
Er.Vinod kumar verma ${ }^{1}$, Vipin Tripathi ${ }^{2}$, Vivek Kumar Verma ${ }^{3}$, Mohd Nuzaif ${ }^{4}$ \\ ${ }^{I}$ Assistant Professor Mechanical Engineering Department SHIATS, Allahabad, India \\ ${ }^{2}$ Student Shiats Allahabad, India \\ ${ }^{3}$ Student Shiats Allahabad, India \\ ${ }^{4}$ Student Shiats Allahabad, India
}

\begin{abstract}
This paper presents one such effort to explore the potential of convex lens to be used for water heating application. In this work, manufactured using six convex lenses and copper receiver tube, for the better performance one side of copper receiver tube converted in to circular to flat The two axis manual tracking system is used to continuous track the sun. Testing was performed on 24nd April, 2014 in solar energy lab SHIATS Allahabad with different mass flow rates. The conversion of solar energy from sun into the useful form is done by the CSP collectors. CSP system is found suitable for its application for the hot water for domestic and the industrial applications and emerges as a best candidate to replace the conventional fossil fuels based systems in eco-friendly manner. The various system designs are developed and commercialized till date viz. parabolic trough collector, Fresnel trough collector etc. but still there is a scope for the system having low thermal losses and high efficiency. The CSP is designed with the six convex lenses (10cm. each dia.) and double copper receiver of size 8mm I.D. and 9 mm O.D. The system is tested during the month of April 2014, when the solar intensity measured was, from $981 \mathrm{~W} / \mathrm{m} 2$ to $1008 \mathrm{~W} / \mathrm{m} 2$.
\end{abstract}

Keywords: CSP using convex lens, thermal efficiency, overall heat transfer coefficient, transmissivity etc.

\section{INTRODUCTION}

Solar energy is a clean and abundant energy resource that can be used to supplement many of your energy needs. Solar energy can be utilized as a form of heat, such as solar water heating, and as electricity, such as solar photo voltaic. Solar water heating systems are commonly referred to in the industry as Solar Domestic Hot Water (SDHW) systems. Water heating is one of the most cost-effective uses of solar energy, providing hot water for showers, dishwashers and clothes washers. Every year, several thousands of new solar water heaters are installed worldwide. The increasing demand and depleting fossil fuels are forcing for the use of the renewable energy sources. For India, the dependability on expensive import of crude oil to fulfill its growing energy demand in spite of abundance of solar radiation incidence over it causes to think about non-conventional ways. The solar energy can be utilized in two ways as Solar PV and Solar thermal. But still the solar technologies available for conversion are not mature leaving the scope for newer efficient methods. Out of the two, solar thermal devices are more efficient than solar PV. The solar thermal energy conversion is of concentrated type (CSP) as in parabolic trough and non-concentrating type as in flat plate collectors. The highest efficiencies available with the concentrated solar thermal devices is in the range of $40-50 \%$ only. The losses in the CSP are mainly in the reflection losses, receiver losses which need to be addressed in order to improve the efficiency of the CSP technology. With the development of the CSP technologies, the concentration ratio increases resulting in the substantial increase in the outlet temperature from 100 to the $1500{ }^{\circ} \mathrm{C}$. Hence the applications of the CSP technologies increase beyond the water heating only.

Demand is one of society's foremost challenges for the next half-century. The importance of this pervasive problem and the perplexing technical difficulty of solving it require a concerted national effort marshalling our most advanced scientific and technological capabilities. The conversion of diffuse source of energy from sun into the useful form is done by the CSP collectors. CSP system is found its application for the hot water and steams required for domestic and the industrial applications and emerge as a best candidate to replace the conventional fossil fuels based systems in eco-friendly manner. Still there is a scope for a development of CSP systems to improve the efficiency with low cost. Of the available CSP technologies the generally point focused technologies are widely used for high temperature applications despite high initial cost due to their high efficiencies compare to their counterpart. The peak solar efficiency achieved with the line focused collectors is $20-21 \%$ only. And that of the point focused collectors is $45-$ $50 \%$. But the main barrier in wide spread of the CSP system is high initial cost and the lower efficiency. Hence there is a big scope for R\&D to find the low cost and efficient solutions. Solar technologies are broadly characterized as either passive or active depending on the way they capture, convert and distribute sunlight. Active solar techniques use photovoltaic panels, pumps, and fans to convert sunlight into useful outputs. Passive solar techniques include selecting materials with favorable thermal properties, designing spaces that naturally circulate air, and referencing the position of a building to the Sun. Active solar 
technologies increase the supply of energy and are considered supply side technologies, while passive solar technologies reduce the need for alternate resources and are generally considered demand side technologies.

\section{BASIC ABOUT CONVEX LENS 2}

\section{1 (CSP) Concentrated Solar Power Technology1}

a) Every ray of light that passes through the lens, going through the optical center (geometric center of the lens), is refracted without deviation.

b) Any beam incident on the lens along a direction parallel to the optical axis is refracted such that it, or its extension in the opposite direction, passes through a point called the optical axis of the lens image focus $(F)$.

c) All light beams leaving the lens parallel to its optical axis has to pass through is a point Called the optical axis of the lens focus object $(\mathrm{F})$ before incising the lens. The focuses are significant points of the optical axis of special importance in optical lenses. There are two of them. The object focuses and image focus. The object focus is a point of the optical axis whose image is formed at infinity and the axis. The image focus is a point on the optical axis which is the image of a point located at infinity and the axis.

A piece of glass in the shape of intersection of two spherical Volumes would be a thin spherical lens. The intersection of these two spherical surfaces would be a circle and the plane passing through this circle is called plane of the Lens.

Concentration of incident rays by Convex lens the special characteristic of the lens is that when an infinite Set of parallel rays parallel to the principal axis of the lens fall on the lens surface, they are concentrated at a single point by these lens. The principal axis is the axis perpendicular to the plane of the lens. The point at which all the incident rays are focused by the lens is called focal point and its distance from the plane of lens is called as focal length.

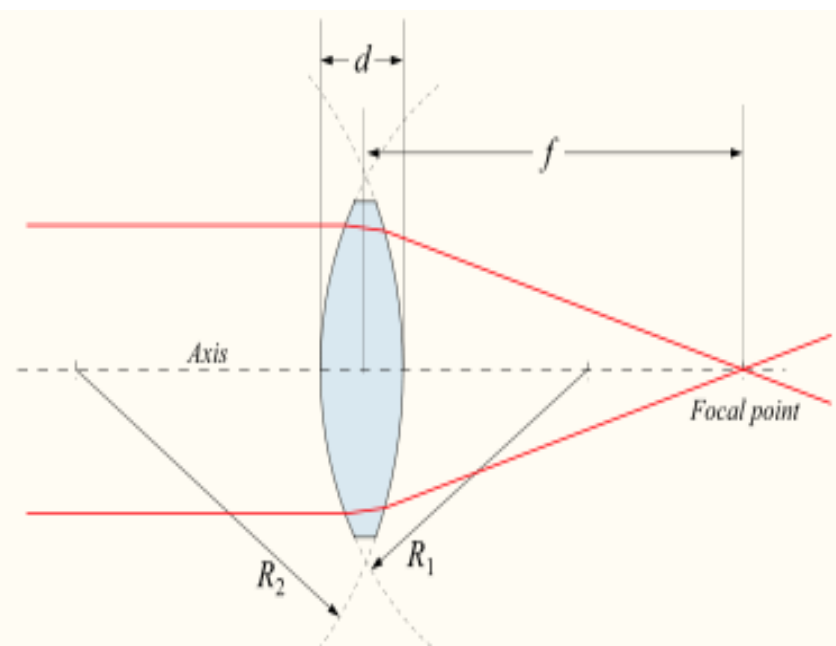

Positive (converging) lens

Fig-1: Concentration of incident rays by Convex lens

\subsection{Convex Lens CSP Panel 2}

Some initial experiments were carried out to determine some important parameters in order to determine the potential of the proposed work. The Convex lens of the Magnifying Glass available easily in local markets of dia. $10 \mathrm{~cm}$ was chosen. The focal length of this lens was found out to be $18.5 \mathrm{cms}$ and the maximum temperature attended at the focal point is found out to be $195^{\circ} \mathrm{c}$ by placing a thermocouple junction under direct solar radiations. The Solar Collector is a Rectangular box of size 74cms $x$ 14cms $\boldsymbol{x} 21 \mathrm{cms}$ made of plywood of $\mathbf{8} \mathbf{~ m m}$ thickness. At the top of the box, six circular holes of $10 \mathrm{cms}$ dia. are cut where convex lens were fixed. The lenses used were the simple Convex Lens from Magnifying glass which is available easily in local markets. The lenses are fixed in the holes of the receiver box by Plaster of Paris (POP) as it provides easily removal of the lens for further adjustments. The Receiver is made of a Copper tube $6,25 \mathrm{~mm}$ (1/4th inch) in dia. and $1 \mathrm{~mm}$ thickness. The length of the tube is $180 \mathrm{cms}$ and is fitted in double line in the Panel Box at its focal length. The tubes were provided with Flow valve to control the flow rate of water through the panel. The incident Solar rays on the six lens area are concentrated at the focal point where the receiver tube is placed. Six thermocouples (Jtype) are attached near the focus point in order to determine the surface temperatures and study the variation of these temperatures along the length of tube. The Sun is Tracked from East to West with axis of the receiver tube along North-South directions and the collector is inclined. The inclination of the collector can be adjusted such that the incident radiations are normal to the collector surface. Two Flow Control Valves were installed at the inlet and outlet of the panel to precisely control the flow rate of water in the panel.

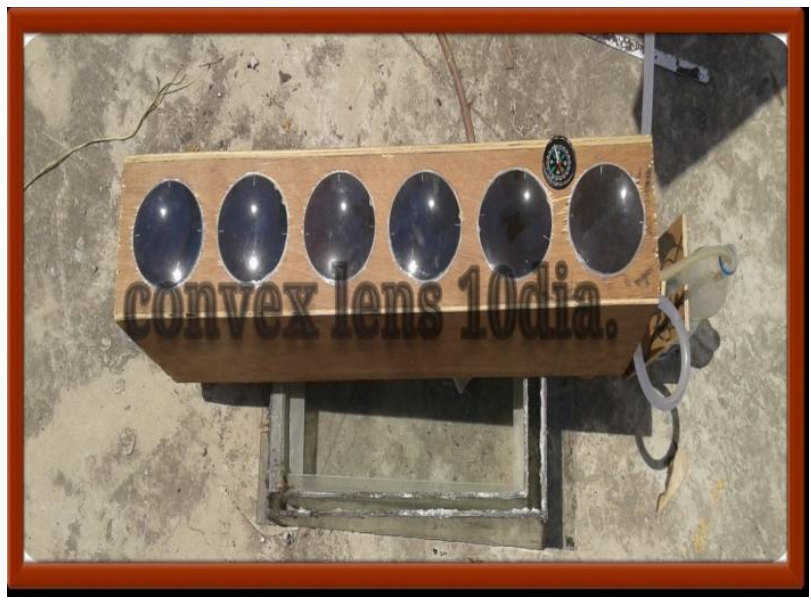

Fig- 2 Convex lens solar collector experimental set up

CSP systems are mainly contained:

1- Manual Tracking Mechanism

2- Copper Receiver Tube

3- Convex Lenses

4- Flow Valve

5- Adjustable Screw

6- Thermocouples T1-T6 
The testing was carried out two days on 23ed and 24th of APRIL, 2014 on clear sunny days. Lux meter was used to measure the solar intensity and anemometer was used to measure the wind speed during the test. The air and water temperatures were measured using thermometers. The Heating of the water take place due to the high temperatures attained by the receiver surface and the variation of the outlet water temperature with change in solar intensity and time of the day were noted during the test.

\section{GOVERNING PERFORMANCE EQUATION}

The collector efficiency $(\eta)$ is the measure of the collector performance and is defined as the ratio of the useful heat gain over any time period to the incident solar energy over the same time period.

$$
\eta=\mathrm{Qu} /(\mathrm{I} \times \mathrm{Aa}) \times 100
$$

Where, $\mathrm{Qu}=$ Useful Energy transfer to the working fluid in Watts

$\mathrm{I}=$ Total Solar Radiation Incident on the unit area in (W/m2)

$\mathrm{A}=$ Collector Area in $\mathrm{m} 2$.

The rate of useful heat transfer to the to the working fluid is given by,
Where,

$\eta=$ collector efficiency

$\mathrm{Aa}=$ collector area

$\mathrm{FR}=$ Heat removal factor

$\mathrm{S}=$ Useful Solar Flux for which the total solar Radiations incident is to be measured.

$\mathrm{Ul}=$ Overall heat loss Co-efficient

$\mathrm{C}=$ Concentration Ratio for the given lens.

$\mathrm{Tp}=$ Receiver tube surface Temperature $\left({ }^{\circ} \mathrm{K}\right)$

$\mathrm{Ta}=$ Ambient Air Temperature $\left({ }^{\circ} \mathrm{K}\right)$.

\section{CONCLUSIONS}

The aim of this paper explains the performance of CSP in the Allahabad climatic condition. This observation write on the basis of six reading, in the set up the angel of inclination is $30^{\circ} \mathrm{c}$,direction of CSP E/W , average inlet time $11.09 \mathrm{am}$., average outlet time $11.58 \mathrm{am}$., time taken 18.5 minute, at this time the inlet water temperature $36.83^{0 \mathrm{c}}$, and outlet temperature $46^{0 \mathrm{c}}$.for the 1 liter of water.

On the basis of this reading I reach this conclusion when we are use this type solar water heating system per after 18.5 minute find 1 liter of water at $46^{\circ} \mathrm{c}$ this temperature is sufficient for bathing purpose. When this type of solar water heating system use in whole day find 32.43 liter water per 10 hour.

$$
\mathrm{Qu}=\{\mathrm{Aa} \times \mathrm{FR} \times[\mathrm{S}-\mathrm{U} \mathrm{H} / \mathrm{C} \times(\mathrm{Ts}-\mathrm{Ta})]\} / \mathrm{I} \times \mathrm{A} / \times 100
$$

Table 1: Normal Water Date-24-04-2014

\begin{tabular}{|l|l|l|l|l|l|l|l|l|}
\hline 8.no. & angel & direction & $\begin{array}{l}\text { Inlet } \\
\text { time } \\
\text { time }\end{array}$ & $\begin{array}{l}0 \text { ut let duration } \\
\text { Inlet } \\
\text { water } \\
\text { temp. } \\
\text { water } \\
\text { temp. }\end{array}$ & $\begin{array}{l}\text { 0ut let } \\
\text { 0utput in liter }\end{array}$ \\
\hline 1 & $30^{\circ}$ & $\mathrm{E} / \mathrm{W}$ & $\begin{array}{l}10: 15 \\
\mathrm{AM}\end{array}$ & $10: 28$ & 13 & $35^{\circ} \mathrm{C}$ & $40.5^{\circ} \mathrm{C}$ & 1 \\
\hline 2 & $30^{\circ}$ & $\mathrm{E} / \mathrm{W}$ & $\begin{array}{l}10: 30 \\
\mathrm{AM}\end{array}$ & $11: 08$ & 38 & $38^{\circ} \mathrm{C}$ & $55.5^{\circ} \mathrm{C}$ & 1 \\
\hline 3 & $30^{\circ}$ & $\mathrm{E} / \mathrm{W}$ & $\begin{array}{l}11: 09 \\
\mathrm{AM}\end{array}$ & $11: 22$ & 13 & $37^{\circ} \mathrm{C}$ & $41.5^{\circ} \mathrm{C}$ & 1 \\
\hline 4 & $30^{\circ}$ & $\mathrm{E} / \mathrm{W}$ & $\begin{array}{l}11: 30 \\
\mathrm{AM}\end{array}$ & $11: 57$ & 27 & $36^{\circ} \mathrm{C}$ & $54.5^{\circ} \mathrm{C}$ & 1 \\
\hline 5 & $30^{\circ}$ & $\mathrm{E} / \mathrm{W}$ & $\begin{array}{l}11: 59 \\
\mathrm{AM}\end{array}$ & $12: 08$ & 8 & $37^{\circ} \mathrm{C}$ & $41^{\circ} \mathrm{C}$ & 1 \\
\hline 6 & $30^{\circ}$ & $\mathrm{E} / \mathrm{W}$ & $\begin{array}{l}12: 15 \\
\mathrm{AM}\end{array}$ & $12: 27$ & 12 & $38^{\circ} \mathrm{C}$ & $43^{\circ} \mathrm{C}$ & 1 \\
\hline & & & $\begin{array}{l}11.09 \mathrm{am} \\
11.58 \mathrm{am}\end{array}$ & $\begin{array}{l}18.5 \\
\mathrm{minute}\end{array}$ & 36.83 & 46 & 1 \\
\hline
\end{tabular}




\section{REFERENCES}

[1] S. S. Kale, Prof. N.N. Shinde “ Design and Development of CSP Using Convex Lenses for Domestic Water Heating and Steam Generation". International Journal of Mechanical Engineering and Research Volume 1 Issue 2 (Page, 74-78), ISSN: 2277-8128

[2] Ashok kumar gupta "Experimental investigation of convex lens concentrating solar power collector prototype performance" IJIERM Issue:2348-4918

[3] G.D. Rai, "Solar Energy Utilization", published by Khanna publishers, 5th Edition, 1999

[4] S. P. Sukhatme, J k Nayak, "Solar Energy, Principle of Thermal Collection and Storage", published by Tata McGraw-Hill publishing Company, Third Edition, 2008.

[5] Y. Raja Shekhar, K.V. Sharma and M. Basaveswara Rao," Evaluation of Heat Loss Coefficients in Solar Flat Plate Collectors", published in APRN journal of engineering and applied sciences, Vol.4, no.5, july2009, pp. 15-19 